\title{
MENSURANDO A INOVAÇÃO POR MEIO DO GRAU DE INOVAÇÃO SETORIAL E DO CARACTERÍSTICO SETORIAL DE INOVAÇÃO
}

\section{Marcos Roberto Gois de Oliveira}

Doutor em Economia pela Universidade Federal de Pernambuco - PIMES/UFPE

Professor do Programa de Pós-Graduação em Administração da Universidade Federal de PernambucoPROPAD/UFPE

mrgois@hotmail.com (Brasil)

\section{André Marques Cavalcanti}

Doutor em Engenharia Elétrica pela Universidade Federal de Pernambuco - PPGEE/UFPE

Professor da Universidade Federal de Pernambuco - UFPE

andremarques2008@gmail.com (Brasil)

\section{Fernando Gomes de Paiva Júnior}

Doutor em Administração pela Universidade Federal de Minas Gerais - UFMG

Professor da Universidade Federal de Pernambuco - UFPE

fernando.paivajr@gmail.com (Brasil)

\section{Denilson Bezerra Marques}

Doutor em Sociologia pela Universidade Federal de Pernambuco- UFPE

Professor da Universidade Federal de Pernambuco - UFPE

marquesdb@gmail.com (Brasil)

\section{RESUMO}

Este estudo analisa as dimensões setoriais de inovação no radar de inovação de micro e pequenas empresas (MPE) do estado de Pernambuco. O radar propõe 13 dimensões na composição da métrica, mas sem as especificidades de cada setor. Na realização de comparações entre características de diferentes setores, é importante considerar que cada um deles atribui pesos distintos a cada dimensão. Assim, busca-se estabelecer um processo de relativização do radar de inovação com procedimentos denominados Característico de Inovação Setorial (CIS) e Grau de Inovação Setorial (GIS), que permitem normalizar as diferentes dimensões do radar de inovação de um setor para efeito de comparação e entre suas dimensões. O GIS normaliza o método tradicional com base nas dimensões da inovação, considerando aspectos da heterogeneidade setorial. Já o CIS identifica oportunidade de crescimento em relação ao melhor desempenho. Para sua validação, o método foi aplicado usando oito amostras de 25 MPE de oito diferentes setores.

Palavras-chave: Grau de inovação setorial, característica de inovação setorial, mensuração da inovação, radar da inovação, micro e pequena empresa. 



\section{INTRODUÇÃO}

Algumas nações que enfrentam uma grande expansão econômica, como a China e o Brasil, estão diante do dilema de crescimento econômico sem aumentar a inflação. Aparentemente, a China procura um incremento da produtividade, visto que dispõe de razoável quantidade de insumos básicos como mão de obra e capital. Segundo Meireles et al. (2010), a produção é incrementada por meio de expansão da mão de obra e do capital, caso não haja mudança no paradigma produtivo.

No caso brasileiro, a expansão da produção não é mais permitida via intensificação do uso dos fatores de produção. Tal observação é corroborada pelo aumento de salários de algumas profissões atreladas diretamente à produção industrial, como as engenharias, fato que indica estar o Brasil se aproximando do limite da capacidade produtiva.

Uma solução para aumentar a produção e reduzir os efeitos inflacionários é a mudança de paradigmas dessa produção. Por meio da inovação, as empresas podem, em tese, produzir mais sem o aumento significativo nos insumos, como forma de transformar o modo como se produz.

A inovação tem sido a nova moeda da competição global, na medida em que países competem ferozmente por novos mercados em um contexto onde a capacidade de criar novas ideias é considerada marca registrada do sucesso nacional, como lembra Senger et al. (2006). A competição tem apontado para captação de capital de risco associada à pesquisa e desenvolvimento (P\&D), adicionados a talentos inovativos e, assim, sendo delimitadas regiões densas de inovação de onde se potencializa a emergência de oportunidades. Portanto, a inovação passa a se constituir força orientadora das políticas públicas de muitos países.

Diante da relevância crescente do tema inovação no desenvolvimento das nações, os pesquisadores propuseram tipologias para medir o grau de inovação organizacional. Dentre tais pesquisadores destacam-se: Schumpeter (1984) e Sawhney e Chen (2010). Tal avanço metodológico culminou na criação de instrumentos de análise de performance inovadora de empresas, a exemplo do radar de inovação, ferramenta composta de 12 indicadores, aqui designados como dimensões. Isto posto, é imperativo refletir que a eficácia e abrangência desse método são questionáveis no que se refere a sua aplicação na avaliação das MPE.

A crítica que se destaca neste estudo diz respeito à dificuldade de homogeneizar e comparar a inovação entre MPE de diferentes setores econômicos. A forma sugerida por Sawhney e Chen (2010) compreende a avaliação das 12 dimensões componentes do radar de inovação. A aplicação deste método avaliativo fica difícil quando se trata de empresas de diferentes atividades econômicas (aqui definidas como setores), pois se toma como pressuposto básico que para uma empresa ser reconhecida como plenamente inovadora, necessariamente teria que se desenvolver em todas as dimensões 
indicadas pelo método proposto. Entretanto, os interesses e formas de atuar no mercado fazem com que, por sua natureza, as empresas de determinado setor se desenvolvam mais em algumas das dimensões, enquanto que para outras dimensões não há nenhum significado relevante no que tange às empresas desse setor.

Pode ser esperado que uma empresa com alto desempenho em inovação seja aquela que obtenha alto grau de desenvolvimento nas dimensões de interesse para aquele setor, e não em todas as dimensões definidas na avaliação do Radar de inovação. A partir desse pressuposto, se não forem consideradas a existência de diferenças interssetoriais no que se refere à inovação, criam-se distorções nas análises de inovação entre setores e dificuldades para comparações entre empresas.

Reconhece-se que empresas com alto grau de inovação não necessariamente têm desenvolvidas todas as dimensões do radar de inovação. Logo, uma vez identificadas às diferenças existentes entre setores, passa-se a ter a necessidade de apontar ou direcionar ações capazes de promover a elevação do desempenho a partir da análise dos potencias de desenvolvimento de cada empresa nos seus setores, identificando-se, assim, os potencias de crescimento em inovação apontados por um característico de inovação setorial é possível se nortear ações para dimensões específicas referentes às empresas de cada setor em análise.

Uma solução aqui proposta é desenvolver um modelo de avaliação das dimensões do radar de inovação, relevantes para empresas de determinado setor, aqui designado por vetor Característico de Inovação Setorial $(C I S)$. Para a análise entre empresas de setores diferentes, cabe propor a operacionalização de um modelo de normalização das diferenças entre as dimensões apuradas como relevantes, aqui designado por Grau de Inovação Setorial (GIS), aplicados ambos (GIS e CIS) às MPE. A relevância deste estudo, do ponto de vista acadêmico, reside na possibilidade da realização e busca das evidências da inovação relacionada com a ontogenia e a ontologia das empresas. Do ponto de vista da aplicação prática, a implementação deste mecanismo de análise reside no fato de se definir a indicação do investimento voltado para a potencialização de dimensões que demonstrem evidências de potencias de desenvolvimento em inovação para aquele determinado setor. 


\section{REFERENCIAL TEÓRICO}

Neste capítulo, são apresentadas definições de inovação e algumas formas de mensurar a inovação, começando pelo critério proposto por Schumpeter (1984), chegando às modificações sugeridas por Bachmann e Destefani (2008), com base nos estudos de Sawhney et al. (2006).

\subsection{Inovação - Definições}

O termo inovação pode ser definido de várias formas, dependendo da perspectiva de interesse. No entanto, a maioria das definições apresenta uma visão restrita e geralmente orientada para tecnologia com foco em $\mathrm{P} \& \mathrm{D}$, desenvolvimento de novo produto ou a dicotomia de produtos/processos.

Garcia e Calantone (2002) definem inovação como processos interativos usados na exploração do potencial de mercado de uma invenção baseado em tecnologia. Esse processo simula graus de inovação e necessita de uma tipologia para descrever tipos diferentes de inovação. McDermott e O'Conner (2002) apresentam a inovação como sendo uma ou várias novas tecnologias ou suas combinações que oferecem benefícios. Essa visão enfatiza o papel da inovação como um processo de introdução no mercado de uma nova tecnologia por sistema de adoção e difusão.

Nesse fluxo, a inovação é compreendida como processo de $\mathrm{P} \& \mathrm{D}$ ou invenção dirigida à tecnologia. Em um segundo grupo de definição, inovação passa a representar desenvolvimento de um novo produto. Por exemplo, Hauser et al. (2006) e Han et al. (1998) definem inovação como sendo o processo de trazer produtos e serviços novos para comercializar.

Um terceiro grupo de estudos inclui processos na extensão de inovação e a visão de inovação como uma dicotomia de produto/processo. Por exemplo, Tushman e Nadler (1986) definem inovação como a criação de qualquer produto, serviço e processo que são inusitados a uma unidade de negócio. Nesse conceito, inovação de processo envolve o ato de criar maneiras diferentes de desenvolver produtos novos ou melhorar a eficiência do processo.

Essa dicotomia ainda é tecnologia orientada. Portanto, considerando os pontos de vista funcionais da literatura existente, a maioria dos estudos na área leva em conta uma relação estreita entre inovação orientada para tecnologia ou produto. Nesse sentido, a função do marketing reside em ressaltar as competências centrais da empresa, as quais devem ser flexíveis e mutáveis, sempre tendo em vista as necessidades igualmente mutáveis dos clientes.

Revista de Administração e Inovação, São Paulo, v. 11, n.1, p.115-137, jan./mar. 2014. 
Espera-se que o marketing contribua com a integração da rede de empresas parceiras e que realize permanente monitoramento do mercado, levantando e processando informações acerca dele em uma velocidade maior do que a dos concorrentes (Limeira, 2005).

Existe, no campo das proposições teóricas, grande sintonia entre os pressupostos inerentes à abordagem das redes e à abordagem da inovação, tendo o empreendedor como agente catalisador. Aí ele atua conectando recursos dispersos, mas conhecidos, presentes em diferentes redes ou grupo sociais lançando mão, para isso, de conexões e contatos privilegiados, e vai, assim, ocupando e preenchendo os espaços vazios, mas facilmente perceptíveis no mercado. No entanto, o ato de empreender encontra-se também associado à habilidade de permanentemente forjar novos e revolucionários conceitos de negócios, reunindo recursos que poderiam parecer, à primeira vista, incompatíveis entre si (Vale et al., 2008).

Neste estudo, a inovação é vista como uma ação capaz de gerar valor à organização por meio de um fazer novo, ou seja, inovação implica na mudança de paradigma interno à empresa, mas não necessariamente uma mudança de paradigma empresarial. Nesse contexto, é possível inovar em comercialização dos produtos, desenvolvimento de canais de distribuição, criação de novos produtos ou processos, desenvolvimento de novas ações de marketing e outras ações que impactem no valor da empresa de forma sustentável e permanente.

\subsection{Mensurando a Inovação em uma Organização}

A dificuldade de configurar as definições de inovação mais adequadas reside em estabelecer um procedimento de medição ou definir um processo de como inovar. Garcia (2008) apresenta uma tipologia para a inovação pautada em quatro princípios: tecnológico, comercial, organizacional e institucional. Esse autor aborda a inovação de forma ampliada e dá o tom de complexidade.

Outra forma de gerar inovação é por meio da holística proposta por Schumpeter (1984), de modo a definir dimensões para a inovação. Segundo ele, a inovação pode surgir sob a dimensão de um novo produto, novo processo, pela procura de novos mercados, desenvolvimento de novas fontes de matérias-primas ou novas estruturas de mercado.

Com base no modelo de Schumpeter (1984), foi definida a principal referência internacional para a medição da inovação: o Manual de Oslo (2004), que permite a efetuação de comparações entre trabalhos relacionados com a inovação a partir das diretrizes propostas.

Em Schumpeter (1984), propõe-se uma ferramenta denominada Radar de Inovação, que relaciona as dimensões pelas quais uma empresa pode procurar caminhos para inovar. O Radar da Inovação reúne quatro dimensões principais, a saber: ofertas criadas; clientes atendidos; processos 
empregados; e praça. Tais dimensões compõem a base de referência para se determinar a inovação. No entanto, Sawhney et al. (2006) percebem que as empresas procuram outros caminhos para alcançar patamares mais elevados de competitividade por meio da inovação.

\subsection{As Dimensões da Inovação - O Radar da Inovação}

Além das quatro dimensões apresentadas por Schumpeter (1984), Sawhney et al. (2006) propõem adicionar mais oito dimensões: Plataforma, Marca, Soluções, Relacionamento, Agregação de Valor, Organização, Cadeia de Fornecimento e Rede.

Bachmann e Destefani (2008) acrescentam às 12 dimensões de Sawhney et al. (2006) o conceito de ambiente propício à inovação. Tal situação pode ser percebida pelo aporte de recursos humanos à empresa, com formação facilitadora do processo de incorporação e implementação da cultura de inovação e que está de acordo com o estudo de Brito et al. (2009).

No Quadro 1, são apresentadas as dimensões da inovação propostas por Sawhney et al. (2006) e complementadas por Bachmann e Destefani (2008).

A maioria das pesquisas no campo da inovação argumenta que inovações são fundamentais para o sucesso empresarial, porém seus resultados empíricos são inconclusivos pelo fato de concluírem como positivo, negativo ou sem efeito as inovações no desempenho da empresa (Akgün et al., 2009). Acredita-se que a controvérsia pode ter suas origens na medição da inovação. Até agora, é alternadamente medida como entradas de inovação (O' Regan et al., 2006) ou como saídas de inovação. Além disso, há falta de acordo entre os autores sobre como medir o efeito da inovação no desempenho da empresa.

\begin{tabular}{|l|l|}
\hline Dimensão & Definição \\
\hline Oferta & Desenvolvimento de produtos com características inovadoras. \\
\hline Processos & $\begin{array}{l}\text { Redesenho dos processos produtivos de modo a permitir incremento de } \\
\text { eficiência operacional. }\end{array}$ \\
\hline Clientes & Identificar necessidades dos clientes, ou novos nichos de mercado. \\
\hline Praça & Identificar novas formas de comercialização e/ou distribuição. \\
\hline Plataforma & $\begin{array}{l}\text { Relaciona-se com a adaptabilidade do sistema de produção face à } \\
\text { diversidade de produtos demandados. }\end{array}$ \\
\hline Marca & Formas de como as empresas transmitem aos clientes os seus valores. \\
\hline Soluções & Sistemas ou mecanismos para simplificar as dificuldades do cliente. \\
\hline Relacionamento & Relaciona-se com a experiência do cliente com a empresa. \\
\hline Agregação de Valor & $\begin{array}{l}\text { Melhorar a forma de captar o valor dos produtos percebido por cliente e } \\
\text { fornecedores. }\end{array}$ \\
\hline Organização & Melhorar a estrutura da empresa. \\
\hline Cadeia de Fornecimento & $\begin{array}{l}\text { Incrementar a logística com os fornecedores e clientes, seja interno ou } \\
\text { externo. }\end{array}$ \\
\hline Rede & Comunicação entre os elos da cadeia de fornecimento. \\
\hline
\end{tabular}

Revista de Administração e Inovação, São Paulo, v. 11, n.1, p.115-137, jan./mar. 2014. 


\begin{tabular}{|l|l|}
\hline Dimensão & Definição \\
\hline Ambiência Inovadora & $\begin{array}{l}\text { Relaciona-se com os profissionais que compõem a empresa e que } \\
\text { colaboram com a cultura da inovação. }\end{array}$ \\
\hline \\
Quadro 1- Definição das dimensões da inovação
\end{tabular}

Fonte: Adaptado de Sawhney et al. (2006 e 2010) e Bachmann e Destefani (2008)

Já em Ketokivi et al. (2010), a discussão reafirma o potencial da aplicação do radar da inovação de Sawhney et al. (2006) como uma ferrramenta eficaz para avaliação não só da inovação tecnológica como também de processos e serviços. Em sua pesquisa, o autor identifica que, dentre as 12 dimensões avalidas, oito tiveram influência no crescimento das empresas pesquisadas.

\section{PROCEDIMENTO METODOLÓGICO}

A metodologia aplicada neste estudo passa por quatro etapas: montagem e aplicação dos questionários; tratamento das informações; construção do modelo e cálculo do Característico Setorial de Inovação (CIS) e do Grau de Inovação Setorial (GIS).

A primeira etapa da pesquisa visa captar dados sobre cada dimensão a partir da aplicação do questionário desenvolvido para atender ao projeto Agentes Locais de Inovação (ALI) (SEBRAE, 2010). O questionário é composto de 40 construtos agrupados em 13 categorias, as quais coincidem com as dimensões da inovação propostas por Sawhney et al. (2006 e 2010), em conjunto com a dimensão ambiência inovadora (Bachmann e Destefani, 2008). Considerando o questionário utilizado e apresentado por Sawhney et al. (2006), foi mantida toda sua estrutura com a inclusão da décima terceira dimensão que trata da ambiência inovadora. Esse questionário está detalhado em (Bachmann e Destefani, 2008). Na dimensão inovadora investiga-se: identificação do uso de fontes externas de conhecimento quanto a consultorias ou apoio de entidades reconhecidas como de fomento à pesquisa $\mathrm{e}$ à inovação; identificação da existência de sistemáticas de busca de novas informações ou tecnologias por meio de congressos, seminários e associações técnicas empresariais; identificação da ocorrência de práticas de aquisição de novos conhecimentos ou tecnologias junto a fornecedores ou clientes; averiguação se a empresa possui sistemática de aquisição de informações técnicas; averiguação se a empresa tem investido em atividades de P\&D com registro de patentes; verificação se a empresa tem sistemática de lançamento de produtos ou processos tecnologicamente novos no mercado; averiguação se a empresa já utilizou ou utiliza fontes de financiamento da inovação; e, por fim, verificação se a empresa possui sistemática de coleta de novas ideias junto a clientes, parceiros, fornecedores e colaboradores.

Foram realizadas entrevistas semiestruturadas junto a 200 dirigentes de MPE, no período entre os anos de 2010 e 2011. Essas empresas são oriundas dos seguintes setores: indústria de móveis, 
panificação, indústria de plásticos, gastronomia e turismo, aplicações de gesso, serviço de eletrometalmecânica, comércio varejista e indústria de confecções do estado de Pernambuco. Para cada um dos 8 setores supracitados foram analisadas 25 empresas.

Os setores foram escolhidos em função de suas peculiaridades, sobretudo no tocante às possibilidades de se inovar. Assim, foram utilizados para validar e testar o método de determinação do Característico Setorial de Inovação (CIS). Os questionários foram respondidos pelos dirigentes das empresas selecionadas por amostras.

As amostras não podem ser classificadas como aleatórias, porque a primeira incursão às empresas foi realizada de forma aleatória, uma vez que algumas delas não desejaram participar do Projeto. Nesses casos, as empresas foram substituídas com base no critério de acessibilidade (indicação das empresas já participantes, proximidade geográfica, etc.).

O modelo aqui apresentado possibilita aprimoramento da análise do radar de inovação conforme as 13 dimensões de Bachmann \& Destefani (2008). Cada dimensão está composta de um conjunto de perguntas, cujo valor médio reflete a característica em termos de inovação da empresa nesta dimensão específica (Bachmann \& Destefani, 2008). De acordo com os autores, cada pergunta oferece três opções de respostas, conforme o Quadro 2 a seguir:

\begin{tabular}{|l|l|}
\hline GRAU & DESCRIÇÃO \\
\hline 5 & Empresa inovadora para o item em pauta \\
\hline 3 & Inovação em um estágio intermediário \\
\hline 1 & Empresa não inovadora ou pouco inovadora \\
\hline
\end{tabular}

Quadro 2: Critério de classificação das empresas por grau de estágio de inovação Fonte: Adaptado de Bachmann \& Destefani (2008)

De acordo com Ketokivi e Ali-Yrkkö (2010), ações de inovação têm um impacto em múltiplas dimensões do radar, mas de forma distinta para cada empresa. Esses autores sinalizaram que, independente da origem da inovação, quer seja no lançamento de um novo produto, quer de uma estratégia de venda, haverá um incremento das demais dimensões da inovação. Entretanto, a propagação do impacto entre as dimensões tem efeitos distintos conforme a situação de cada empresa, sobretudo naquelas procedentes de setores distintos.

A dificuldade do radar de inovação em medir a inovação global remete à heterogeneidade de cada setor. Exemplificando: o lançamento de um novo produto no mercado na indústria de telefonia móvel tem um impacto superior ao lançamento de um novo produto em uma empresa de panificação, a depender do mix de produtos. Ketokivi e Ali-Yrkko (2010) apontaram que empresas de base tecnológica têm uma capacidade maior de gerar inovação com atividades de P\&D do que empresas de setores pouco intensivos em tecnologia. Entretanto, ambas podem ser consideradas inovadoras em determinados aspectos do radar.

Revista de Administração e Inovação, São Paulo, v. 11, n.1, p.115-137, jan./mar. 2014. 
Diante da constatação da heterogeneidade dos setores, é proposto o grau de inovação setorial por empresa (GIS), que é definido pela Equação 1:

$$
G I S=\sum_{k=1}^{13} p_{k} D_{M k}
$$

onde:

$D_{i k}$ é o valor da dimensão da inovação $k$ para a empresa $i$;

$D_{i M}$ é o valor da dimensão da inovação $k$ para o setor.

Já o peso das dimensões da inovação $p_{k}$ é obtido pelo seguinte modelo de otimização:

$$
\operatorname{Max} \sum_{k=1}^{13} p_{k} D_{M k}
$$

$$
\begin{aligned}
\text { sujeito a: } & \sum_{k=1}^{13} p_{k}=1 \\
& p_{k} \geq 0,05 \quad \text { para } \forall k
\end{aligned}
$$

Onde $D_{M k}$ é o valor da dimensão da inovação $k$ para o setor $M$ e o peso das dimensões da inovação $p_{k}$ é obtido pelo modelo de otimização declarado em (2).

De forma complementar ao GIS, é possível destacar as dimensões que apresentam melhor desempenho para determinado setor, por intermédio do uso das funções de atribuição de características de inovação setorial, aqui declarado como CIS. Essa métrica tem por objetivo ressaltar as distâncias entre o valor médio de uma dimensão que teve o melhor desempenho em determinado setor e os valores obtidos por cada dimensão desse mesmo setor. Indica quais dimensões estão próximas de seu benchmark interno, cuja métrica é fornecida pela Equação 3:

$$
\text { Medd }_{k s}=\left(1-\frac{\text { Maxmedd }_{s}-d_{i k}}{\text { Maxmedd }_{s}}\right) * 5
$$

onde:

- $M e d d_{k s}$ é o valor médio ajustado da dimensão de inovação $k$ para o setor $s$ - indica quão próximo do benchmark o setor se encontra em alguma dimensão.

- Maxmedd $_{s}$ é o valor Máximo dos valores médios das $k$ dimensão da inovação para as $i$ empresas do setor $s$;

- $d_{i k}$ é o valor médio da dimensão da inovação $k$ do setor $\mathrm{s}$. 
Define-se o CIS médio setorial das 13 dimensões como sendo dada na Equação 4:

$$
\operatorname{MedCIS}=\left(\operatorname{Medd}_{1, s}, . ., \operatorname{Medd}_{13, s}\right)
$$

No entanto, é necessário identificar claramente o quanto cada dimensão deve se desenvolver para atingir o seu valor máximo. Busca-se, portanto, identificar o potencial de crescimento a partir da métrica declarada na equação 5:

$$
\operatorname{Maxd}_{k s}=\left(\frac{\operatorname{Maxd}_{i k}-d_{i k}}{\operatorname{Maxd}_{i k}}\right) * 5
$$

onde:

- $M A X d_{k s}$ é o valor Máximo ajustado das $k$ dimensões de inovação para o setor $s$-indica o quanto aquela dimensão pode crescer em relação ao concorrente do mesmo setor. Quanto maior, maior o potencial de crescimento;

- $\operatorname{Maxd}_{i k}$ é o valor Máximo dos valores das dimensões da inovação $k$ para as $i$ empresas do setor $s$.

Define-se o CIS setorial como sendo:

$$
\operatorname{MaxCIS}_{s}=\left(\operatorname{Maxd}_{1, s}, \ldots, \operatorname{Maxd}_{13, s}\right)
$$

\section{APLICAÇÃO}

\subsection{Comparação Entre os Setores - O Método Tradicional}

Nas Tabelas 1, 2, e 3 são apresentadas as estatísticas básicas das dimensões da inovação das 25 empresas de cada um dos setores pesquisados obtidas a partir dos instrumentos de coleta de informações. Observar-se que os resultados a seguir apresentados são válidos para as empresas estudadas, ou seja, refletem a situação em termo de inovação deste grupo de empresas Pernambucanas avaliadas no período de 2010 a 2011.

Revista de Administração e Inovação, São Paulo, v. 11, n.1, p.115-137, jan./mar. 2014. 
Como exemplo da análise, é realizada uma comparação entre os setores de móveis e panificação, onde o estrato do primeiro setor apresenta vantagem em termos de inovação nas seguintes dimensões: marca, relacionamento, processos, organização e presença. Essa vantagem pode ser atribuída às características de determinadas empresas do setor de móveis das MPE, pelo menos do estado de Pernambuco, que demonstram necessidade de compor uma marca forte e de manter um bom relacionamento com os clientes e funcionários. Já no setor de panificação, é evidente a necessidade de se manter um leque de produtos e uma plataforma tecnológica de modo a agregar valor à determinada empresa.

\begin{tabular}{|l|r|r|r|r|r|r|r|r|r|}
\hline \multirow{2}{*}{ Dimensão } & \multicolumn{3}{|c|}{ Eletrometalmecânica } & \multicolumn{3}{c|}{ Gesso } & \multicolumn{2}{c|}{ Indústria de Confecçóes } \\
\cline { 2 - 10 } & Média & Máx. & Mín. & Média & \multicolumn{1}{c|}{ Máx. } & \multicolumn{1}{c|}{ Mín. } & Média & \multicolumn{1}{c|}{ Máx. } & \multicolumn{1}{c|}{ Mín. } \\
\hline Oferta & 1,21 & 2,67 & 1 & 1,31 & 3,33 & 1 & 2,43 & 4 & 1,33 \\
\hline Plataforma & 1,92 & 3 & 1 & 1,2 & 3 & 1 & 3,96 & 5 & 2 \\
\hline Marca & 2,44 & 4 & 2 & 1,92 & 4 & 1 & 2,84 & 4 & 1 \\
\hline Clientes & 1,68 & 2,5 & 1,5 & 1,66 & 4 & 1 & 2,4 & 4 & 1 \\
\hline Soluções & 1,24 & 3 & 1 & 1,12 & 2 & 1 & 1,32 & 3 & 1 \\
\hline Relacionamento & 1,36 & 3 & 1 & 1,36 & 3 & 1 & 1,56 & 4 & 1 \\
\hline Agregação de Valor & 1,04 & 2 & 1 & 1,24 & 3 & 1 & 1,08 & 2 & 1 \\
\hline Processos & 1,02 & 1,4 & 1 & 1,1 & 2,2 & 1 & 1,21 & 1,8 & 1 \\
\hline Organização & 1,06 & 2 & 1 & 1,12 & 3 & 1 & 1,32 & 2,5 & 1 \\
\hline Cadeia de Fornecimento & 1 & 1 & 1 & 1,4 & 3 & 1 & 1,4 & 3 & 1 \\
\hline Presença & 1,08 & 3 & 1 & 1,2 & 3 & 1 & 1,48 & 4 & 1 \\
\hline Rede & 1 & 1 & 1 & 1,08 & 3 & 1 & 1,48 & 5 & 1 \\
\hline Ambiência Inovadora & 1,14 & 1,5 & 1 & 1,27 & 3 & 1 & 1,36 & 2 & 1 \\
\hline
\end{tabular}

Tabela 1 - Estatísticas das dimensões da inovação dos setores de eletrometalmecânica, gesso e indústria de confecções Fonte: Os autores

\begin{tabular}{|l|r|r|r|r|r|r|r|r|r|}
\hline \multirow{2}{*}{ Dimensão } & \multicolumn{3}{|c|}{ Indústria de Móveis } & \multicolumn{3}{c|}{ Indústria de Plásticos } & \multicolumn{3}{c|}{ Comércio Varejista } \\
\cline { 2 - 10 } & Média & Máx. & Mín. & \multicolumn{1}{c|}{ Média } & Máx. & Mín. & Média & Máx. & \multicolumn{1}{c|}{ Mín. } \\
\hline Oferta & 2,2 & 3 & 1,3 & 1,64 & 3 & 1 & 2,63 & 4 & 1 \\
\hline Plataforma & 2,2 & 4 & 1 & 2,52 & 5 & 1 & 4,48 & 5 & 2 \\
\hline Marca & 3 & 4 & 1 & 2,28 & 5 & 1 & 1,68 & 4 & 1 \\
\hline Clientes & 2,2 & 3,5 & 1 & 2,3 & 4,5 & 1 & 2,66 & 3,5 & 1,5 \\
\hline Soluções & 1,8 & 4 & 1 & 1,48 & 5 & 1 & 3,12 & 5 & 1 \\
\hline Relacionamento & 1,8 & 4 & 1 & 1,84 & 4 & 1 & 2,44 & 5 & 1 \\
\hline Agregação de Valor & 2,2 & 4 & 1 & 1,48 & 4 & 1 & 2,28 & 5 & 1 \\
\hline Processos & 1,7 & 2,6 & 1 & 1,32 & 3 & 1 & 1,35 & 2,6 & 1 \\
\hline Organização & 2,2 & 3 & 1,5 & 1,72 & 4 & 1 & 2,28 & 4,5 & 1 \\
\hline Cadeia de Fornecimento & 1 & 1 & 1 & 1,32 & 5 & 1 & 2,12 & 5 & 1 \\
\hline Presença & 1,4 & 4 & 1 & 1,48 & 3 & 1 & 1,84 & 4 & 1 \\
\hline Rede & 1,3 & 3 & 1 & 2,44 & 5 & 1 & 1,4 & 5 & 1 \\
\hline
\end{tabular}




\begin{tabular}{|l|l|l|l|l|l|l|l|l|l|}
\hline Ambiência Inovadora & 2 & 2,8 & 1 & 1,53 & 3 & 1 & 1,86 & 3,75 & 1 \\
\hline
\end{tabular}

Tabela 2 - Estatísticas das dimensões da inovação das indústrias de móveis, plásticos e comércio varejista Fonte: Os autores

\begin{tabular}{|l|r|r|r|r|r|r|}
\hline \multirow{2}{*}{\multicolumn{1}{|c|}{ Dimensão }} & \multicolumn{3}{|c|}{ Gastronomia e Turismo } & \multicolumn{3}{c|}{ Panificação } \\
\cline { 2 - 7 } & Média & Máximo & Mínimo & Média & Máximo & Mínimo \\
\hline Oferta & 2,12 & 4,00 & 1,00 & 2,70 & 3,70 & 1,00 \\
\hline Plataforma & 2,40 & 5,00 & 1,00 & 3,20 & 5,00 & 1,00 \\
\hline Marca & 1,76 & 3,00 & 1,00 & 2,40 & 4,00 & 1,00 \\
\hline Clientes & 1,94 & 3,00 & 1,00 & 3,00 & 3,50 & 1,00 \\
\hline Soluções & 1,92 & 4,00 & 1,00 & 4,00 & 5,00 & 1,00 \\
\hline Relacionamento & 1,72 & 4,00 & 1,00 & 1,30 & 4,00 & 1,00 \\
\hline Agregação de Valor & 2,40 & 5,00 & 1,00 & 2,80 & 4,00 & 1,00 \\
\hline Processos & 1,64 & 3,40 & 1,00 & 1,50 & 4,20 & 1,00 \\
\hline Organização & 2,24 & 3,50 & 1,00 & 2,10 & 4,50 & 1,00 \\
\hline Cadeia de Fornecimento & 2,84 & 5,00 & 1,00 & 1,50 & 5,00 & 1,00 \\
\hline Presença & 2,64 & 5,00 & 1,00 & 1,40 & 4,00 & 1,00 \\
\hline Rede & 2,52 & 5,00 & 1,00 & 1,40 & 5,00 & 1,00 \\
\hline Ambiência Inovadora & 1,83 & 2,50 & 1,00 & 2,40 & 3,50 & 1,00 \\
\hline
\end{tabular}

Tabela 3 - Estatísticas das dimensões da inovação dos setores de gastronomia, turismo e panificação Fonte: Os autores

A Figura 1 mostra o potencial de cada setor do exemplo em relação à inovação. Assim, as empresas de panificação possuem um benchmark mais elástico, entretanto, o setor não demonstra potencial para ampliar a base de inovação. Já o setor de móveis tem um espaço mais amplo para inovar, mas as empresas não possuem um benchmark adequado para orientá-las.

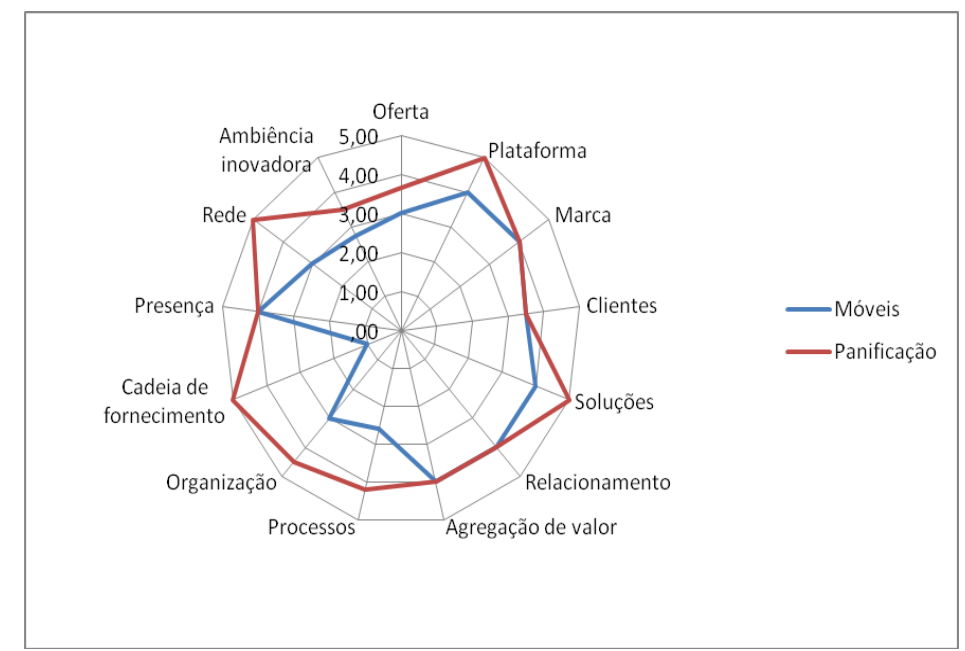

Figura 1 - Radar de inovação referencial para os setores de móveis e panificação Fonte: Os autores 
Na Figura 2, é apresentado o radar de inovação com as dimensões médias dos setores mais inovadores e menos inovadores analisados neste estudo, com base no sistema de mensuração tradicional.

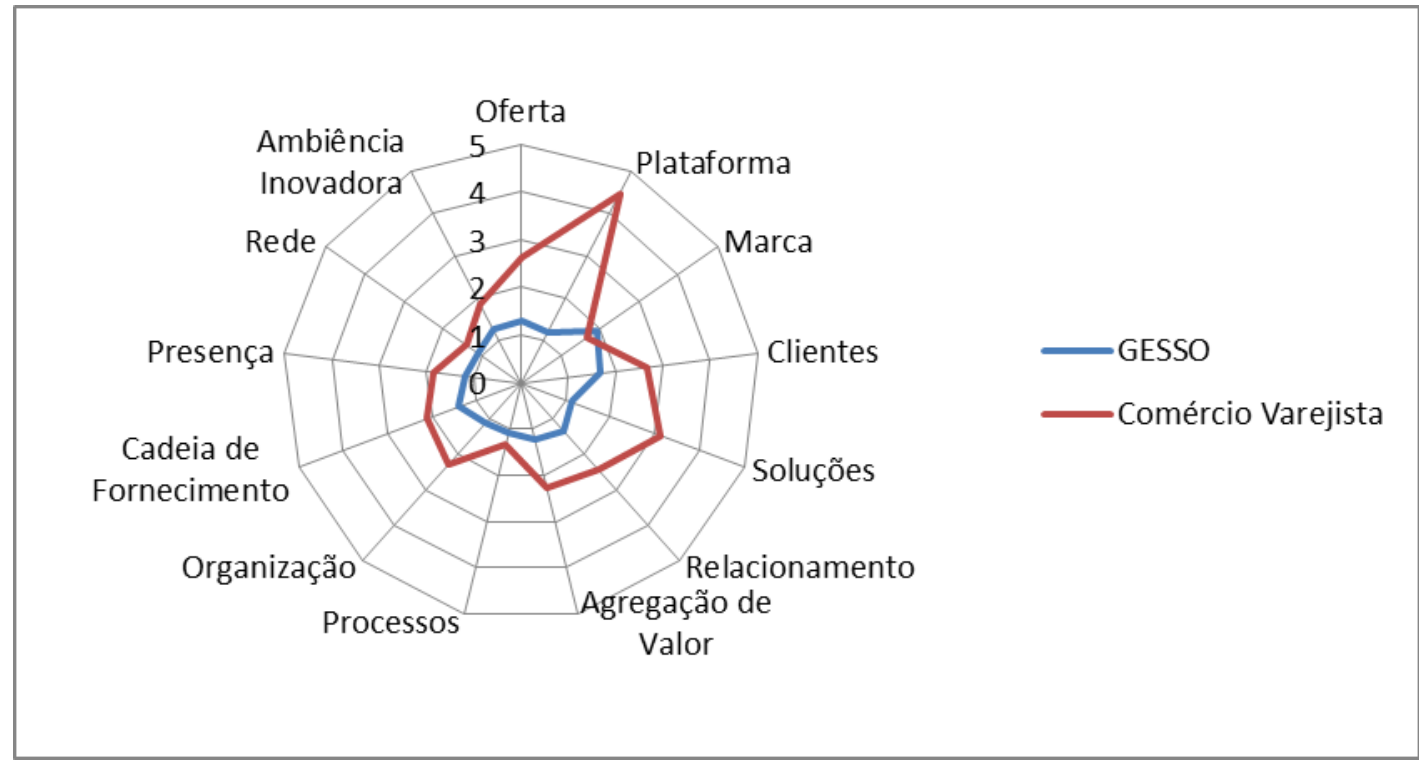

Figura 2 - Radar de inovação médio para os setores de gesso e comércio varejista Fonte: Os autores

\subsection{Comparação entre os Setores - Uma Visão a Partir do Grau de Inovação Setorial}

Há uma modificação do grau de inovação tradicional para o setorial de ambos os setores em função da modificação dos pesos quando comparados às dimensões da inovação. Tal alteração ocorre no sentido de se incrementar a relevância das dimensões mais significativas para cada setor.

Na Tabela 4, são apresentados os pesos calculados de acordo com a Equação (3) para todos os oito setores. Nesta seção, constam as dimensões mais relevantes para cada setor. Com base nesta tabela, são calculados os Graus de Inovação Setorial (GIS) para cada setor e, a partir deles, os índices de cada empresa.

As micro e pequenas empresas estudadas nos setores pernambucanos em epígrafe não utilizaram as dimensões rede, tão pouco ambiência inovadora para incrementar a inovação. Tais empresas não buscaram em ambientes externos à organização meios de agregar soluções inovadoras. Já a dimensão plataforma, relacionada com a estrutura produtiva, constitui fonte de soluções inovadoras para os setores com vocação industrial, como é o caso de panificação, eletrometalmecânica, confecções e plástico. A dimensão clientes recebe um destaque do setor de panificação, enquanto que marcas e plataforma, como citado acima, parecem representar o forte do setor moveleiro 
pernambucano. Cadeia de fornecimento é considerada crítica para os setores de plástico e de turismo e gastronomia.

Tabela 4 - Pesos das dimensões da inovação para definição do grau de inovação setorial

\begin{tabular}{|l|r|r|r|r|r|r|r|r|}
\hline \multirow{2}{*}{\multicolumn{1}{|c|}{ Dimensão }} & \multicolumn{7}{|c|}{ Setor } \\
\cline { 2 - 10 } & Móveis & $\begin{array}{c}\text { Pani- } \\
\text { ficação }\end{array}$ & $\begin{array}{c}\text { Eletrometal- } \\
\text { mecânica }\end{array}$ & Gesso & Plásticos & $\begin{array}{c}\text { Turismo e } \\
\text { Gastronomia }\end{array}$ & $\begin{array}{c}\text { Confec- } \\
\text { ções }\end{array}$ & $\begin{array}{c}\text { Comercio } \\
\text { Varejista }\end{array}$ \\
\hline Oferta & 0,05 & 0,05 & 0,10 & 0,05 & 0,05 & 0,15 & 0,11 & 0,16 \\
\hline Plataforma & 0,22 & 0,16 & 0,18 & 0,05 & 0,19 & 0,13 & 0,22 & 0,05 \\
\hline Marca & 0,17 & 0,05 & 0,05 & 0,11 & 0,05 & 0,05 & 0,05 & 0,05 \\
\hline Clientes & 0,05 & 0,17 & 0,05 & 0,13 & 0,11 & 0,05 & 0,05 & 0,05 \\
\hline Soluções & 0,05 & 0,13 & 0,12 & 0,21 & 0,05 & 0,05 & 0,05 & 0,05 \\
\hline Relacionamento & 0,05 & 0,05 & 0,10 & 0,05 & 0,05 & 0,05 & 0,05 & 0,05 \\
\hline $\begin{array}{l}\text { Agregação de } \\
\text { Valor }\end{array}$ & 0,05 & 0,10 & 0,05 & 0,05 & 0,05 & 0,10 & 0,05 & 0,05 \\
\hline Processos & 0,05 & 0,05 & 0,05 & 0,05 & 0,10 & 0,05 & 0,10 & 0,05 \\
\hline Organização & 0,11 & 0,05 & 0,05 & 0,05 & 0,05 & 0,05 & 0,05 & 0,11 \\
\hline $\begin{array}{l}\text { Cadeia de } \\
\text { Fornecimento }\end{array}$ & 0,05 & 0,05 & 0,05 & 0,05 & 0,15 & 0,17 & 0,12 & 0,05 \\
\hline Presença & 0,05 & 0,10 & 0,10 & 0,05 & 0,05 & 0,05 & 0,05 & 0,23 \\
\hline Rede & 0,05 & 0,05 & 0,05 & 0,05 & 0,05 & 0,05 & 0,05 & 0,05 \\
\hline $\begin{array}{l}\text { Ambiência } \\
\text { Inovadora }\end{array}$ & 0,05 & 0,05 & 0,05 & 0,05 & 0,05 & 0,05 & 0,05 & 0,05 \\
\hline
\end{tabular}

Tabela 4 - Pesos das dimensões da inovação para definição do grau de inovação setorial

Fonte: Os autores

A Tabela 5 apresenta as estatísticas das dimensões da inovação média por setor por ordem decrescente, onde o grau de inovação é calculado como a média aritmética das dimensões da inovação. Já o grau de inovação setorial é calculado de acordo com a Equação (3). A avaliação à luz do GIS posiciona o setor de panificação como o mais inovador entre os pesquisados e apresenta o setor de confecções como o quarto mais inovador (de acordo com a Tabela 7, o setor está em situação de igualdade estatística com comercio, turismo e móveis), enquanto que o grau de inovação tradicional o coloca apenas na quinta posição.

\begin{tabular}{|l|r|r|l|}
\hline \multicolumn{1}{|c|}{ Setor } & $\begin{array}{c}\text { Grau de } \\
\text { inovação }\end{array}$ & $\begin{array}{c}\text { Grau de } \\
\text { inovação setorial }\end{array}$ & \multicolumn{1}{c|}{ Setor } \\
\hline Panificação & 2,3 & 2,6 & Panificação \\
\hline Comércio Varejista & 2,3 & 2,4 & Comércio Varejista \\
\hline Turismo e Gastronomia & 2,1 & 2,3 & Turismo e Gastronomia \\
\hline Móveis & 1,9 & 2,2 & Confecções \\
\hline Confecções & 1,8 & 2,1 & Móveis \\
\hline Plásticos & 1,8 & 1,9 & Plásticos \\
\hline Eletrometalmecânica & 1,3 & 1,5 & Eletrometalmecânica \\
\hline Gesso & 1,3 & 1,3 & Gesso \\
\hline
\end{tabular}

Tabela 5 - Estatísticas das dimensões da inovação média por setor Fonte: Os autores 
As Tabelas 6 e 7 complementam a Tabela 5, ao ser aplicado o teste de Wilcoxon para averiguação de diferença entre médias.

De acordo com a Tabela 6, os setores de panificação e comércio são equivalentes em termo de inovação medido pelo grau de inovação tradicional. O mesmo ocorre com os setores moveleiro, de confecções e de plásticos. Os dois setores com menor vocação para inovação, eletrometalmecânica e gesso, possuem o grau de inovação tradicional similar, do ponto de vista estatístico.

\begin{tabular}{|l|c|c|c|c|l|l|l|r|}
\hline & Panificação & Móveis & Eletro & Gesso & Plástico & Gastronomia & Confecções & Comercio \\
\hline Panificação & 1,000 & 0,000 & 0,000 & 0,000 & 0,000 & 0,001 & 0,000 & 0,616 \\
\hline Móveis & 0,000 & 1,000 & 0,000 & 0,000 & 0,013 & 0,024 & 0,083 & 0,000 \\
\hline Eletro & 0,000 & 0,000 & 1,000 & 0,385 & 0,000 & 0,000 & 0,000 & 0,000 \\
\hline Gesso & 0,000 & 0,000 & 0,385 & 1,000 & 0,000 & 0,000 & 0,000 & 0,000 \\
\hline Plástico & 0,000 & 0,013 & 0,000 & 0,000 & 1,000 & 0,002 & 0,116 & 0,000 \\
\hline Gastronomia & 0,001 & 0,024 & 0,000 & 0,000 & 0,002 & 1,000 & 0,001 & 0,001 \\
\hline Confecções & 0,000 & 0,083 & 0,000 & 0,000 & 0,116 & 0,001 & 1,000 & 0,000 \\
\hline Comércio & 0,616 & 0,000 & 0,000 & 0,000 & 0,000 & 0,001 & 0,000 & 1,000 \\
\hline
\end{tabular}

Tabela 6 - Teste de Wilcoxon para diferença entre médias para o grau de inovação tradicional

Fonte: Os autores

A Tabela 7 apresenta o setor de Gastronomia com o GIS estatisticamente equivalente aos setores de móveis, confecções e comércio (possível heterogeneidade do setor de turismo e gastronomia). Nos demais setores, há uma evidente dispersão e um ordenamento mais bem definido do grau de inovação setorial.

\begin{tabular}{|l|l|l|l|l|l|l|l|r|}
\hline & Panificação & Móveis & Eletro & Gesso & Plástico & Gastronomia & Confecções & Comércio \\
\hline Panificação & 1,000 & 0,000 & 0,000 & 0,000 & 0,000 & 0,000 & 0,000 & 0,000 \\
\hline Móveis & 0,000 & 1,000 & 0,000 & 0,000 & 0,004 & 0,376 & 0,027 & 0,009 \\
\hline Eletro & 0,000 & 0,000 & 1,000 & 0,001 & 0,000 & 0,000 & 0,000 & 0,000 \\
\hline Gesso & 0,000 & 0,000 & 0,001 & 1,000 & 0,000 & 0,000 & 0,000 & 0,000 \\
\hline Plástico & 0,000 & 0,004 & 0,000 & 0,000 & 1,000 & 0,003 & 0,001 & 0,001 \\
\hline Gastronomia & 0,000 & 0,376 & 0,000 & 0,000 & 0,003 & 1,000 & 0,631 & 0,218 \\
\hline Confecções & 0,000 & 0,027 & 0,000 & 0,000 & 0,001 & 0,631 & 1,000 & 0,021 \\
\hline Comércio & 0,000 & 0,009 & 0,000 & 0,000 & 0,001 & 0,218 & 0,021 & 1,000 \\
\hline
\end{tabular}

Tabela 7 - Teste de Wilcoxon para diferença entre médias para o grau de inovação setorial

Fonte: Os autores

Já as Tabelas 8 e 9, construídas com base na Equação (1), apresentam o GIS, a média aritmética da inovação e a média ponderada da inovação para as empresas de dois setores: indústria de móveis e panificação. As empresas cujo GIS esteja abaixo de 1,0 se apresentam com o grau de inovação inferior às demais empresas do setor. 
A análise das tabelas permite inferir facilmente que de forma comparativa a inovação deve se fazer mais presente nos setores de panificação, móveis, eletrometalmecânica e gesso, nessa ordem. A referência para cada um dos setores deve ser, respectivamente, de 2,2;1,9;1,5 e 1,3. Uma empresa que tiver um Grau de inovação simples de 2,0 estará bem posicionada se pertencer ao setor de eletrometalmecânica e gesso, mas terá dificuldades nos setores de panificação e móveis.

\begin{tabular}{|c|c|c|c|c|c|c|c|c|c|c|c|}
\hline \multicolumn{3}{|c|}{ Panificação } & \multicolumn{3}{|c|}{ Móveis } & \multicolumn{3}{|c|}{ Eletrometalmecânica } & \multicolumn{3}{|c|}{ Gesso } \\
\hline $\begin{array}{c}\text { GI } \\
\text { simples }\end{array}$ & $\begin{array}{l}\text { GI pon- } \\
\text { derado }\end{array}$ & GIS & $\begin{array}{c}\text { GI } \\
\text { simples }\end{array}$ & $\begin{array}{c}\text { GI pon- } \\
\text { derado }\end{array}$ & GIS & $\begin{array}{c}\text { GI } \\
\text { simples }\end{array}$ & $\begin{array}{l}\text { GI pon- } \\
\text { derado }\end{array}$ & GIS & $\begin{array}{c}\text { GI } \\
\text { simples }\end{array}$ & $\begin{array}{l}\text { GI pon- } \\
\text { derado }\end{array}$ & GIS \\
\hline 4,2 & 4,2 & 1,61 & 2,8 & 3,0 & 1,43 & 2,1 & 2,4 & 1,58 & 2,6 & 2,4 & 1,88 \\
\hline 2,9 & 3,4 & 1,29 & 2,6 & 2,9 & $\mathbf{1 , 3 6}$ & 1,5 & 1,5 & $\mathbf{1 , 0 3}$ & 1,7 & 1,6 & 1,29 \\
\hline 3,1 & 3,3 & 1,25 & 2,4 & 2,5 & 1,21 & 1,5 & 1,5 & 1,02 & 1,8 & 1,5 & 1,18 \\
\hline 2,4 & 2,8 & 1,07 & 2,2 & 2,5 & 1,17 & 1,5 & 1,5 & 1,01 & 1,6 & 1,5 & 1,16 \\
\hline 2,4 & 2,8 & 1,07 & 2,6 & 2,4 & 1,14 & 1,4 & 1,5 & 0,99 & 1,5 & 1,5 & 1,16 \\
\hline 2,4 & 2,8 & $\mathbf{1 , 0 7}$ & 2,1 & 2,4 & 1,13 & 1,5 & 1,5 & $\mathbf{0 , 9 9}$ & 1,3 & 1,4 & 1,13 \\
\hline 2,4 & 2,8 & $\mathbf{1 , 0 7}$ & 2,1 & 2,3 & $\mathbf{1 , 1 1}$ & 1,3 & 1,5 & $\mathbf{0 , 9 8}$ & 1,5 & 1,4 & 1,11 \\
\hline 2,4 & 2,8 & $\mathbf{1 , 0 7}$ & 2,1 & 2,3 & $\mathbf{1 , 1 1}$ & 1,3 & 1,4 & $\mathbf{0 , 9 4}$ & 1,5 & 1,4 & 1,11 \\
\hline 2,4 & 2,8 & 1,07 & 1,9 & 2,2 & 1,06 & 1,3 & 1,4 & 0,92 & 1,3 & 1,4 & 1,06 \\
\hline 2,4 & 2,8 & $\mathbf{1 , 0 7}$ & 2,1 & 2,2 & 1,05 & 1,3 & 1,4 & $\mathbf{0 , 9 0}$ & 1,3 & 1,3 & 1,03 \\
\hline 2,4 & 2,8 & 1,07 & 2,1 & 2,2 & 1,04 & 1,3 & 1,4 & 0,90 & 1,4 & 1,3 & 1,03 \\
\hline 2,4 & 2,8 & 1,07 & 1,9 & 2,1 & 1,02 & 1,3 & 1,3 & $\mathbf{0 , 8 9}$ & 1,2 & 1,3 & 1,02 \\
\hline 2,4 & 2,8 & 1,07 & 1,9 & 2,1 & 0,99 & 1,3 & 1,3 & $\mathbf{0 , 8 8}$ & 1,2 & 1,3 & 1,02 \\
\hline 2,4 & 2,8 & 1,07 & 1,6 & 2,0 & 0,96 & 1,3 & 1,3 & $\mathbf{0 , 8 7}$ & 1,2 & 1,3 & 0,98 \\
\hline 2,4 & 2,8 & $\mathbf{1 , 0 7}$ & 1,8 & 2,0 & $\mathbf{0 , 9 4}$ & 1,2 & 1,3 & $\mathbf{0 , 8 5}$ & 1,1 & 1,2 & $\mathbf{0 , 9 4}$ \\
\hline 2,4 & 2,8 & 1,07 & 1,8 & 1,9 & $\mathbf{0 , 9 3}$ & 1,2 & 1,3 & $\mathbf{0 , 8 5}$ & 1,1 & 1,1 & 0,89 \\
\hline 2,2 & 2,6 & 1,00 & 1,6 & 1,9 & $\mathbf{0 , 8 9}$ & 1,2 & 1,3 & $\mathbf{0 , 8 5}$ & 1,1 & 1,1 & 0,83 \\
\hline 2,0 & 2,3 & $\mathbf{0 , 9 0}$ & 1,6 & 1,9 & $\mathbf{0 , 8 9}$ & 1,2 & 1,3 & $\mathbf{0 , 8 4}$ & 1,1 & 1,1 & $\mathbf{0 , 8 3}$ \\
\hline 1,9 & 2,3 & $\mathbf{0 , 8 9}$ & 1,6 & 1,8 & $\mathbf{0 , 8 8}$ & 1,2 & 1,3 & $\mathbf{0 , 8 4}$ & 1,1 & 1,1 & 0,83 \\
\hline 2,1 & 2,2 & $\mathbf{0 , 8 5}$ & 1,7 & 1,8 & $\mathbf{0 , 8 8}$ & 1,2 & 1,3 & $\mathbf{0 , 8 4}$ & 1,0 & 1,0 & $\mathbf{0 , 8 0}$ \\
\hline 1,9 & 2,1 & $\mathbf{0 , 8 0}$ & 1,6 & 1,8 & $\mathbf{0 , 8 6}$ & 1,2 & 1,3 & $\mathbf{0 , 8 4}$ & 1,0 & 1,0 & $\mathbf{0 , 7 4}$ \\
\hline 1,8 & 2,0 & $\mathbf{0 , 7 8}$ & 1,6 & 1,7 & $\mathbf{0 , 8 1}$ & 1,2 & 1,3 & $\mathbf{0 , 8 4}$ & 1,0 & 1,0 & 0,74 \\
\hline 1,5 & 1,8 & 0,69 & 1,3 & 1,7 & 0,79 & 1,4 & 1,2 & $\mathbf{0 , 8 3}$ & 1,0 & 1,0 & 0,74 \\
\hline 1,4 & 1,5 & $\mathbf{0 , 5 6}$ & 1,5 & 1,6 & $\mathbf{0 , 7 7}$ & 1,2 & 1,2 & $\mathbf{0 , 7 8}$ & 1,0 & 1,0 & 0,74 \\
\hline 1,3 & 1,2 & 0,47 & 1,4 & 1,6 & 0,76 & 1,2 & 1,1 & 0,74 & 1,0 & 1,0 & 0,74 \\
\hline
\end{tabular}

Tabela 8 - Grau de inovação setorial por empresa - parte 1

Fonte: Os autores 


\begin{tabular}{|c|c|c|c|c|c|c|c|c|c|c|c|}
\hline $\begin{array}{c}\text { GI } \\
\text { simples }\end{array}$ & $\begin{array}{l}\text { GI pon- } \\
\text { derado }\end{array}$ & GIS & $\begin{array}{c}\text { GI } \\
\text { simples }\end{array}$ & $\begin{array}{l}\text { GI pon- } \\
\text { derado }\end{array}$ & GIS & $\begin{array}{c}\text { GI } \\
\text { simples }\end{array}$ & $\begin{array}{l}\text { GI pon- } \\
\text { derado }\end{array}$ & GIS & $\begin{array}{c}\text { GI } \\
\text { simples }\end{array}$ & $\begin{array}{l}\text { GI pon- } \\
\text { derado }\end{array}$ & GIS \\
\hline 3,7 & 4,0 & 2,15 & 3,1 & 3,2 & 1,45 & 2,8 & 3,2 & 1,49 & 2,8 & 3,1 & $\mathbf{1 , 3 8}$ \\
\hline 3,4 & 3,5 & $\mathbf{1 , 8 8}$ & 2,9 & 3,1 & 1,41 & 2,6 & 3,0 & $\mathbf{1 , 3 8}$ & 3,2 & 3,0 & $\mathbf{1 , 3 3}$ \\
\hline 2,2 & 2,5 & $\mathbf{1 , 3 2}$ & 2,4 & 2,7 & 1,25 & 2,3 & 2,7 & 1,22 & 2,6 & 2,9 & $\mathbf{1 , 3 1}$ \\
\hline 2,4 & 2,4 & 1,32 & 2,3 & 2,7 & 1,22 & 2,2 & 2,6 & 1,21 & 2,6 & 2,9 & 1,31 \\
\hline 2,2 & 2,4 & 1,29 & 2,3 & 2,6 & 1,21 & 2,0 & 2,6 & 1,19 & 3,0 & 2,8 & 1,27 \\
\hline 2,2 & 2,2 & 1,19 & 2,6 & 2,6 & 1,20 & 2,2 & 2,5 & 1,17 & 2,9 & 2,7 & 1,20 \\
\hline 1,6 & 1,9 & 1,01 & 2,2 & 2,6 & 1,20 & 1,9 & 2,4 & 1,10 & 2,9 & 2,5 & 1,14 \\
\hline 1,7 & 1,8 & 0,99 & 2,7 & 2,6 & 1,18 & 1,9 & 2,4 & 1,09 & 2,5 & 2,5 & 1,10 \\
\hline 1,8 & 1,8 & 0,95 & 2,3 & 2,5 & 1,15 & 1,9 & 2,4 & 1,09 & 2,5 & 2,3 & 1,03 \\
\hline 1,8 & 1,7 & $\mathbf{0 , 9 3}$ & 2,4 & 2,4 & 1,10 & 1,8 & 2,3 & 1,07 & 2,6 & 2,3 & 1,01 \\
\hline 1,7 & 1,7 & $\mathbf{0 , 9 1}$ & 2,2 & 2,4 & 1,08 & 1,6 & 2,2 & 1,01 & 2,2 & 2,3 & 1,01 \\
\hline 1,8 & 1,7 & 0,91 & 2,2 & 2,3 & 1,07 & 1,9 & 2,2 & 0,99 & 2,2 & 2,2 & 1,00 \\
\hline 1,5 & 1,6 & $\mathbf{0 , 8 9}$ & 2,2 & 2,3 & 1,07 & 2,0 & 2,1 & $\mathbf{0 , 9 8}$ & 2,1 & 2,2 & 1,00 \\
\hline 1,7 & 1,6 & $\mathbf{0 , 8 7}$ & 2,1 & 2,3 & 1,04 & 1,8 & 2,1 & $\mathbf{0 , 9 8}$ & 2,0 & 2,2 & 1,00 \\
\hline 1,6 & 1,6 & $\mathbf{0 , 8 5}$ & 2,1 & 2,3 & $\mathbf{1 , 0 3}$ & 1,8 & 2,1 & $\mathbf{0 , 9 8}$ & 2,3 & 2,2 & $\mathbf{0 , 9 8}$ \\
\hline 1,6 & 1,6 & $\mathbf{0 , 8 5}$ & 2,3 & 2,3 & 1,03 & 2,0 & 2,1 & 0,96 & 2,5 & 2,2 & 0,97 \\
\hline 1,5 & 1,6 & 0,84 & 2,2 & 2,2 & 0,99 & 1,4 & 2,0 & 0,92 & 2,3 & 2,1 & 0,94 \\
\hline 1,7 & 1,6 & $\mathbf{0 , 8 4}$ & 2,1 & 2,1 & 0,96 & 1,7 & 1,9 & $\mathbf{0 , 8 5}$ & 2,3 & 2,1 & 0,94 \\
\hline 1,3 & 1,5 & $\mathbf{0 , 8 2}$ & 1,8 & 1,8 & $\mathbf{0 , 8 2}$ & 1,7 & 1,9 & $\mathbf{0 , 8 5}$ & 1,8 & 1,9 & $\mathbf{0 , 8 7}$ \\
\hline 1,5 & 1,5 & $\mathbf{0 , 8 2}$ & 1,4 & 1,5 & 0,69 & 1,4 & 1,8 & $\mathbf{0 , 8 4}$ & 2,0 & 1,8 & $\mathbf{0 , 8 1}$ \\
\hline 1,3 & 1,4 & $\mathbf{0 , 7 5}$ & 1,5 & 1,5 & 0,68 & 1,5 & 1,7 & $\mathbf{0 , 8 1}$ & 1,7 & 1,7 & $\mathbf{0 , 7 8}$ \\
\hline 1,2 & 1,3 & $\mathbf{0 , 7 0}$ & 1,2 & 1,3 & 0,60 & 1,3 & 1,7 & $\mathbf{0 , 7 9}$ & 1,7 & 1,6 & $\mathbf{0 , 7 3}$ \\
\hline 1,2 & 1,3 & $\mathbf{0 , 6 9}$ & 1,3 & 1,3 & $\mathbf{0 , 6 0}$ & 1,5 & 1,5 & 0,69 & 1,7 & 1,5 & $\mathbf{0 , 6 8}$ \\
\hline 1,1 & 1,2 & 0,66 & 1,2 & 1,2 & 0,54 & 1,4 & 1,5 & 0,68 & 1,5 & 1,4 & 0,63 \\
\hline 1,0 & 1,0 & $\mathbf{0 , 5 5}$ & 1,0 & 1,0 & 0,46 & 1,3 & 1,4 & 0,65 & 1,5 & 1,3 & $\mathbf{0 , 6 0}$ \\
\hline
\end{tabular}

Tabela 9 - Grau de inovação setorial por empresa - parte 2

Fonte: Os autores

\subsection{Comparação Intrassetorial - Uma Aplicação do Característico da Inovação Setorial}

Nas Tabelas 10, 11 e 12 são apresentados os valores dos Característicos MedCIS e MaxCIS para os setores Gesso, Confecções e eletrometalmecânica, indústria de Plástico, Móveis e Comércio varejista, Gastronomia e Turismo e também Panificação. Nesta seção, constam as dimensões mais relevantes para cada setor e aquelas que apresentam potencial de crescimento frente à concorrência.

A partir dos resultados das Tabelas 1, 2 e 3, observa-se a dificuldade de identificar ações prioritárias pela leitura dos valores atribuídos a cada dimensão. Tomando-se, então o MedCIS fornecido pelas Tabelas 10, 11 e 12, é possível identificar as dimensões Plataforma, Marca e Cliente como sendo as de maiores investimentos e atenção por parte dos empresários, entendendo-se que a dimensão Plataforma trata da tecnologia, do modo de fazer e de prestar serviços, dada uma mesma plataforma. 


\begin{tabular}{|l|r|r|r|r|r|r|r|r|r|}
\hline \multirow{2}{*}{ Dimensão } & \multicolumn{3}{|c|}{ Eletrometalmecânica } & \multicolumn{4}{c|}{ Gesso } & \multicolumn{2}{c|}{ Indústria de Confecções } \\
\cline { 2 - 10 } & Média & MedCIS & \multicolumn{1}{c|}{ MaxCIS } & Média & MedCIS & MaxCIS & Média & MedCIS & MaxCIS \\
\hline Oferta & 1,21 & 2,48 & 2,73 & 1,31 & 3,41 & 3,03 & 2,43 & 3,07 & 1,96 \\
\hline Plataforma & 1,92 & 3,93 & 1,80 & 1,2 & 3,13 & 3,00 & 3,96 & 5,00 & 1,04 \\
\hline Marca & 2,44 & 5,00 & 1,95 & 1,92 & 5,00 & 2,60 & 2,84 & 3,59 & 1,45 \\
\hline Clientes & 1,68 & 3,44 & 1,64 & 1,66 & 4,32 & 2,93 & 2,4 & 3,03 & 2,00 \\
\hline Soluções & 1,24 & 2,54 & 2,93 & 1,12 & 2,92 & 2,20 & 1,32 & 1,67 & 2,80 \\
\hline Relacionamento & 1,36 & 2,79 & 2,73 & 1,36 & 3,54 & 2,73 & 1,56 & 1,97 & 3,05 \\
\hline $\begin{array}{l}\text { Agregação de } \\
\text { Valor }\end{array}$ & 1,04 & 2,13 & 2,40 & 1,24 & 3,23 & 2,93 & 1,08 & 1,36 & 2,30 \\
\hline Processos & 1,02 & 2,09 & 1,36 & 1,1 & 2,86 & 2,50 & 1,21 & 1,53 & 1,64 \\
\hline Organização & 1,06 & 2,17 & 2,35 & 1,12 & 2,92 & 3,13 & 1,32 & 1,67 & 2,36 \\
\hline $\begin{array}{l}\text { Cadeia de } \\
\text { Fornecimento }\end{array}$ & 1 & 2,05 & 0,00 & 1,4 & 3,65 & 2,67 & 1,4 & 1,77 & 2,67 \\
\hline Presença & 1,08 & 2,21 & 3,20 & 1,2 & 3,13 & 3,00 & 1,48 & 1,87 & 3,15 \\
\hline Rede & 1 & 2,05 & 0,00 & 1,08 & 2,81 & 3,20 & 1,48 & 1,87 & 3,52 \\
\hline $\begin{array}{l}\text { Ambiência } \\
\text { Inovadora }\end{array}$ & 1,14 & 2,34 & 1,20 & 1,27 & 3,31 & 2,88 & 1,36 & 1,72 & 1,60 \\
\hline
\end{tabular}

Tabela 10 - Característicos por setores Eletrometalmecânica, Gesso e Ind. de confecções

Fonte: Os autores

\begin{tabular}{|l|r|r|r|r|r|r|r|r|r|}
\hline \multirow{2}{*}{\multicolumn{1}{|c|}{ Dimensão }} & \multicolumn{3}{|c|}{ Indústria de Móveis } & \multicolumn{2}{c|}{ Indústria de Plásticos } & \multicolumn{3}{c|}{ Comércio Varejista } \\
\cline { 2 - 11 } & Média & MedCIS & MaxCIS & Média & MedCIS & MaxCIS & Média & MedCIS & MaxCIS \\
\hline Oferta & 2,2 & 3,67 & 1,33 & 1,64 & 3,25 & 2,27 & 2,63 & 2,94 & 1,71 \\
\hline Plataforma & 2,2 & 3,67 & 2,25 & 2,52 & 5,00 & 2,48 & 4,48 & 5,00 & 0,52 \\
\hline Marca & 3 & 5,00 & 1,25 & 2,28 & 4,52 & 2,72 & 1,68 & 1,88 & 2,90 \\
\hline Clientes & 2,2 & 3,67 & 1,86 & 2,3 & 4,56 & 2,44 & 2,66 & 2,97 & 1,20 \\
\hline Soluções & 1,8 & 3,00 & 2,75 & 1,48 & 2,94 & 3,52 & 3,12 & 3,48 & 1,88 \\
\hline Relacionamento & 1,8 & 3,00 & 2,75 & 1,84 & 3,65 & 2,70 & 2,44 & 2,72 & 2,56 \\
\hline Agregação de & 2,2 & 3,67 & 2,25 & 1,48 & 2,94 & 3,15 & 2,28 & 2,54 & 2,72 \\
\hline Valor & 1,7 & 2,83 & 1,73 & 1,32 & 2,62 & 2,80 & 1,35 & 1,51 & 2,40 \\
\hline Processos & 2,2 & 3,67 & 1,33 & 1,72 & 3,41 & 2,85 & 2,28 & 2,54 & 2,47 \\
\hline Organização & 1 & 1,67 & 0,00 & 1,32 & 2,62 & 3,68 & 2,12 & 2,37 & 2,88 \\
\hline Cadeia de & 1,4 & 2,33 & 3,25 & 1,48 & 2,94 & 2,53 & 1,84 & 2,05 & 2,70 \\
\hline Fornecimento & 1,3 & 2,17 & 2,83 & 2,44 & 4,84 & 2,56 & 1,4 & 1,56 & 3,60 \\
\hline Presença & 2 & 3,33 & 1,43 & 1,53 & 3,04 & 2,45 & 1,86 & 2,08 & 2,52 \\
\hline Rede & & & & & & & \\
\hline $\begin{array}{l}\text { Ambiência } \\
\text { Inovadora }\end{array}$ & & & & & & & & & \\
\hline
\end{tabular}

Tabela 11 - Característicos por setores Ind. de Móveis, Ind. Plástico e Comércio Varejista

Fonte: Os autores

\begin{tabular}{|l|r|r|r|r|r|r|}
\hline \multirow{2}{*}{ Dimensão } & \multicolumn{3}{|c|}{ Gastronomia e Turismo } & \multicolumn{3}{c|}{ Panificação } \\
\cline { 2 - 7 } & Média & MedCIS & \multicolumn{1}{c|}{ MaxCIS } & Média & MedCIS & \multicolumn{1}{c|}{ MaxCIS } \\
\hline Oferta & 2,12 & 3,73 & 2,35 & 2,7 & 3,38 & 1,35 \\
\hline Plataforma & 2,4 & 4,23 & 2,60 & 3,2 & 4,00 & 1,80 \\
\hline Marca & 1,76 & 3,10 & 2,07 & 2,4 & 3,00 & 2,00 \\
\hline Clientes & 1,94 & 3,42 & 1,77 & 3 & 3,75 & 0,71 \\
\hline Soluções & 1,92 & 3,38 & 2,60 & 4 & 5,00 & 1,00 \\
\hline Relacionamento & 1,72 & 3,03 & 2,85 & 1,3 & 1,63 & 3,38 \\
\hline
\end{tabular}

Revista de Administração e Inovação, São Paulo, v. 11, n.1, p.115-137, jan./mar. 2014. 


\begin{tabular}{|l|r|r|r|r|r|r|}
\hline \multirow{2}{*}{ Dimensão } & \multicolumn{3}{|c|}{ Gastronomia e Turismo } & \multicolumn{3}{c|}{ Panificação } \\
\cline { 2 - 7 } & Média & MedCIS & MaxCIS & Média & \multicolumn{1}{c|}{ MedCIS } & \multicolumn{1}{c|}{ MaxCIS } \\
\hline Agregação de Valor & 2,4 & 4,23 & 2,60 & 2,8 & 3,50 & 1,50 \\
\hline Processos & 1,64 & 2,89 & 2,59 & 1,5 & 1,88 & 3,21 \\
\hline Organização & 2,24 & 3,94 & 1,80 & 2,1 & 2,63 & 2,67 \\
\hline Cadeia de Fornecimento & 2,84 & 5,00 & 2,16 & 1,5 & 1,88 & 3,50 \\
\hline Presença & 2,64 & 4,65 & 2,36 & 1,4 & 1,75 & 3,25 \\
\hline Rede & 2,52 & 4,44 & 2,48 & 1,4 & 1,75 & 3,60 \\
\hline Ambiência Inovadora & 1,83 & 3,22 & 1,34 & 2,4 & 3,00 & 1,57 \\
\hline
\end{tabular}

Tabela 12 - Característicos por setores Gastronomia e Turismo e Panificação

Fonte: Os autores

Já a dimensão Rede aparece em todos os setores com o MaxCIS, demonstrando-se, assim, a necessidade do fortalecimento com os elos da cadeia de suprimentos, dificuldade esta talvez caracterizada pela capacidade de negociação motivada pelo porte dessas empresas.

Outra dimensão que aparece na maioria das empresas no MaxCIS é Processos, que se refere às atividades usadas na condução das operações internas da empresa, a fim de confeccionar um produto ou prestar um serviço. A motivação para existência dessa necessidade identificada está justificada pela insipiência da condição das empresas pesquisadas, na sua grande maioria, com menos de cinco anos de existência. O que se constata é que a maior justificativa para o fechamento de um grande número de MPE está vinculada à dimensão Processo.

\subsection{Análise dos Resultados}

As MPE normalmente buscam atuar em segmentos de mercado que não estão plenamente atendidos por grandes e médias empresas. Em geral, elas se localizam onde o seu público-alvo se encontra. São empresas que se estabelecem em setores que exigem baixo investimento para implantação e capital de giro e, de certa forma, competem por apresentar produtos e serviços de baixo custo e alto volume de consumo. Essas características fazem com que 98,84\% do total de empresas no estado de Pernambuco sejam compostos por MPE. Portanto, existe um número percentual elevado de MPE em ralação ao total existente de empresas, e sua participação no PIB é da ordem de $20 \%$.

Em função da análise do comportamento dos empresários vinculados às empresas pesquisadas, o que se percebe é que a fatia de mercado alvo dá a impressão de que ele está voltado exclusivamente para o preço, não se valorizando a qualidade. Muitas dessas empresas surgem da falta de oportunidades de empregos, o que obriga o trabalhador desempregado a buscar alternativas de sobrevivência, sem, muitas vezes, ter visão empreendedora e financeira. Dessa forma, essas empresas 
não estão motivadas a realizar melhorias em processos, serviços e produtos, fato que compromete a busca por inovação.

A necessidade de se estabelecer um crescimento econômico sustentável se projeta na busca pela definição de procedimentos que norteiem em quais dimensões deve ser estimulada a inclusão de novas tecnologias e melhorias de processos, como uma necessidade identificada do setor e, em outros casos, quais dimensões devem ser desenvolvidas para fazer frente à concorrência emergente. É também necessário desenvolver ferramentas para auxiliar a identificar diferenciais competitivos que se efetivam por intermédio de uma orientação de desenvolvimento voltado para competição no mercado.

A pesquisa mostra que as empresas dos setores analisados estão em um padrão de inovação caracterizado pela ausência de procedimentos que buscam introduzir uma cultura de inovação, tratando, apenas, daqueles que venham a manter a sua capacidade atual ou dos que revelam incrementos que sejam pouco volumosos, capazes de ser absorvidos sem grandes investimentos. Isso é verificado na análise dos valores de MedCIS e MaxCIS, indicando que não há destaque nos valores médios e que não há um benchmark que represente investimento substancial, portador de certo diferencial competitivo.

Assim, não é por acaso que a dimensão Plataforma, que trata dos componentes comuns e descreve o modo de fazer e prestar serviços, apresente os melhores desempenhos. A partir da leitura dos valores de MedCIS e MaxCIS, é possível concluir que na percepção do empresário esse conjunto de componentes conduz à busca de padrões de excelência, embora a ação ocorra de forma tímida e talvez limitada, pela capacidade de investir em incentivos de políticas de desenvolvimento.

$\mathrm{Na}$ análise realizada a partir do GIS, é possível identificar as dimensões relevantes para cada setor, na visão de empresário, e com base nos dados obtidos no radar. Essas dimensões representam o fortalecimento das suas capacidades mais desenvolvidas.

Levando-se em conta a complexidade de mensurar a inovação e seus efeitos no desempenho empresarial, conforme demonstrado na literatura, é possível verificar aqui a utilização do Radar de inovação com os seus 13 construtos. A combinação do CIS e do GIS permite identificar características setoriais relevantes para incrementar a inovação e facilitar a análise da aplicação dos incentivos voltados para o desenvolvimento a partir da inovação.

Diante da possibilidade de se expandir a pesquisa para um maior número de empresas nos seus diversos níveis de desenvolvimento, bem como, considerar o tempo de existência com essas ferramentas, torna-se possível estabelecer padrões que identifiquem aspectos ontogênicos e ontológicos. Esses aspectos, uma vez mapeados, forneceram informações relevantes para propiciar e identificar ações que permitam rapidamente alavancar os seus efeitos de desenvolvimentos, uma vez

Revista de Administração e Inovação, São Paulo, v. 11, n.1, p.115-137, jan./mar. 2014. 
que se conhecem a forma e o caminho com os quais essas empresas chegam à maturidade em seus ciclos de desenvolvimento.

\section{CONSIDERAÇÕES FINAIS}

Conforme apresentado nas seções anteriores, a inovação pode ser tomada como uma estratégia fundamental para promover o bem-estar da sociedade por meio de sistemas e processos de produção mais eficientes e como modo de se otimizar os recursos definidos por políticas públicas de desenvolvimento.

Considerando ser indiscutível a relevância da inovação no desenvolvimento de uma Nação, Região ou Cidade, também é primordial discutir sobre suas formas de mensuração, sobretudo para que as empresas e instituições de fomento possam ter uma referência para se identificar que ações impulsionadoras de inovação produzem maior efeito. Nesta linha, explica-se o sucesso do radar de inovação no sentido de nortear a medida da inovação. Isso ocorre não apenas no sentido da inovação associada a novos produtos, mas no sentido mais amplo, qual seja, agregar valor à organização por modelos sustentáveis e adaptados às características do setor e flexíveis ao próprio ambiente onde essas empresas estejam localizadas.

No entanto, o radar de inovação, sobretudo o grau de inovação, tem um problema que consiste em não abordar as empresas levando em consideração a heterogeneidade dos setores a que elas pertencem. A proposta apresentada neste estudo sugere o Grau de Inovação Setorial (GIS) como medida para avaliar o grau de inovação de empresas referenciadas com o seu setor de atuação.

O GIS normaliza o radar de inovação com base nas 13 dimensões da inovação, por outro lado, leva em consideração aspectos da heterogeneidade dos setores. Para demonstrar a validade do método proposto foi realizado um estudo de caso que utiliza dados do radar de inovação de 8 setores de MPE localizadas em Pernambuco com 8 amostras de 25 MPE de cada setor.

De uma forma geral, entre os setores e empresas analisadas, o que se desponta como o mais inovador é o de panificação, com evidente ênfase nas dimensões cliente e plataforma, com equilíbrio entre as atividades-fim do setor: produção e atendimento ao cliente. Neste setor, também é identificada a empresa mais inovadora com um grau de inovação setorial de 4,2.

O resultado quantitativo da inovação obtido de cada empresa por meio do GIS permite compará-las não apenas dentro do setor, mas também entre setores, demonstrando-se a possibilidade de uma empresa mediana em termos de inovação, mas situada num setor propenso à inovação, ser considerada mais inovadora que a empresa mais inovadora de um setor com dificuldades naturais para inovar. Assim, a partir do radar normalizado, é possível investir em ações dirigidas preferencialmente 
para onde se possam obter resultados que sejam percebidos pelos clientes ou consumidores de produtos e serviços, de forma diferenciada com evolução sustentável.

Como discutido anteriormente, o MedCIS indica que quanto maior o valor, com limite de cinco, quão próximo da dimensão de melhor desempenho se encontra a dimensão analisada. Já o MaxCIS indica o quão distante se encontra uma determinada dimensão de um setor específico do benchmark do setor naquela dimensão. Então, essas medidas usadas em conjunto com o GIS permite indicar estratégias para desenvolvimento de ações voltadas para as dimensões que efetivamente caracterizam um determinado setor e que devem ser trabalhadas na perspectiva de trazer o melhor resultado.

Quanto aos dados analisados, pode ser destacado, entre os setores e empresas analisadas, o setor mais inovador como sendo o de panificação, com evidente ênfase na dimensão cliente e plataforma com equilíbrio entre suas atividades-fim: produção e atendimento ao cliente. Já o setor mais embrionário e demandante da definição de políticas e incentivos é o de aplicação de Gesso e o de Eletrometalmecânica. Além de apresentarem uma média baixa em cada dimensão, esses setores não exibem destaques significativos de indicações pelo MedCIS e MaxCIS revelando-se, assim, como um setor ainda insipiente, pelo menos, por indução representativa das empresas tomadas na amostra.

Dessa forma, os dados obtidos do Radar de Inovação conjuntamente com o seu característico de inovação (MedCIS e MaxCIS) e o Grau de Inovação Setorial (GIS) permitirão, assim, melhor representação do estado atual de inovação de um setor e quais estratégias adotar para o seu desenvolvimento.

É necessário destacar que os resultados apontados neste estudo são limitados às empresas pesquisadas, não podendo ser compreendidas como uma característica intrínseca a cada setor. Para uma análise que permita generalização dos resultados, é necessário tomar uma amostra representativa daquela região a ser estudada.

\section{REFERÊNCIAS}

Akgün, A.E., Keskin, H., \& Byrne, J., Organizational emotional capability, product and process innovation, and firm performance: an empirical analysis. Journal of Engineering and Technology Management 26, 103-130.2009.

Bachmann, D. L., \& Destefani, J. H. Metodologia para estimar o grau das inovações nas MPE. Curitiba, 2008.

Brito, E. P. Z., Brito, L. A. L., \& Morgatti, F. Inovação e o desempenho empresarial: Lucro ou crescimento? RAE-eletrônica, v. 8, n. 1, Art. 6, jan./jun. 2009.

Revista de Administração e Inovação, São Paulo, v. 11, n.1, p.115-137, jan./mar. 2014. 
Garcia, J. G. Um estudo sobre as formas de inovação e os critérios de avaliação dos prêmios de inovação. Dissertação de mestrado em administração. Universidade de Caxias do Sul, 2008.

Garcia, R., \& Calantone. R. A critical look at technological innovation typology and innovativeness terminology: a literature review. Journal of Product Innovation Management 19(2): 110-132, 2002.

Han, J.K., Kim, N.; Srivastava. R.K. Market Orientation and Organizational Performance: Is Innovation a Missing Link? Journal of Marketing 62(4): 30-45, 1998.

Hauser, J., Tellis, G.J.; \& Griffin, A. Research on Innovation: A Review and Agenda for Marketing Science. Marketing Science, v. 25, n.6, p.687-717, 2006.

Ketokivi, M., \& Ali-Yrkkö, J. Innovation does not equal R\&D: strategic innovation profiles and firm growth. Helsinki, Etla, E. T., The Research Institute of the Finnish Economy, 22p. (Keskusteluaiheita, Discussion Papers; ISSN 0781-6847; No. 1220), 2010.

Limeira, T. M. V., Inovação de Mentalidade. Revista de Administração - RAE, v4, n.2, p.33-37, 2005.

Manual de Oslo. Proposta de diretrizes para coleta e interpretação de dados sobre inovação tecnológica. Organização para Cooperação Econômica e Desenvolvimento: Versão FINEP, 2004.

McDermott, C.M., \& O'CONNER, G.C. Managing radical innovation: an overview of emergent strategy issues. Journal of Product Innovation Management, v.19, p.424-438, 2002.

Meireles, M., Sanches, C., \& De Sordi, J.O. Incorporação tecnológica pelas empresas brasileiras: um estudo da variação em dez anos (1998 a 2008). SIMPÓSIO DE ADMINISTRAÇÃO DA PRODUÇÃO LOGÍSTICA E OPERAÇÕES INTERNACIONAIS, 2010.

O'Regan, N., Ghobadian, \& A., Gallear, D. In search of the drivers of high growth in manufacturing SMEs. Technovation 26, 30-41. 2006.

Oliveira, W.A. Modelos de naturidade: visão geral. Mundo PM. p.611.dez/jan., 2006.

Sawhney, M., Wolcott, R. C., \& Arroniz, I. The 12 Different Ways for Companies to Innovate. MIT Sloan Management Review , v.47, n.3, p.75-81, 2006.

Sawhney, M., \& Chen, J. Defining and measuring business innovation: the Innovation Radar. Electronic copy available em: http://ssrn.com/abstract=1611264, 2010.

Sebrae. Projeto Agentes Locais de Inovação (ALI) em Pernambuco. www.projetoalipe.com.br, 2010.

Senger, P., Scharmer, C.O., Jaworski, J., \& Flowers, B.S. Presence: an exploration of profound change in people, organization and society. Currency Books, 2006.

Schumpeter, J.A. The theory of economic development: an inquiry into profits, capital, credit, interest, and the business cycle. New York, Oxford University Press, 1984.

Tushman, M., \& Nadler, D. Organizing for Innovation. California Management Review, v.28, n.3, p.74-92, 1986.

Vale, G. M. V., Wilkinson, J., \& Amâncio, R. Empreendedorismo, inovação e redes: uma nova abordagem. RAE-eletrônica - v. 7, n. 1, Art. 7, jan./jun. 2008.

Revista de Administração e Inovação, São Paulo, v. 11, n.1, p. 115-137, jan./mar. 2014. 


\title{
MEASURING INNOVATION THROUGH SECTORIAL INNOVATION DEGREE AND OF THE CHARACTERISTIC SECTORAL INNOVATION
}

\begin{abstract}
This study analyzes the innovation sector dimensions in the innovation radar of the micro and small sized firms (MSF) in Pernambuco State. The radar considers 13 dimensions in its composition, but it does not consider each sector characteristics. In carrying out of comparisons among different sectors features, it is important to consider each of them to give distinct weights to each dimension. Thus, a procedure called Sector Innovation Characteristic (SIC) and Sector Innovation Degree (SID) search in this study to establish a process to compare the innovation degree. The SIC allows normalizing the different dimensions of the innovation radar from specific sector for comparison effect between them. The SID normalizes the traditional method on the basis of the innovation dimensions, considering heterogenic sector aspects. The method is validated with application on eight sectors samples with 25 MSF of different sectors.
\end{abstract}

Keywords: Sector innovation degree; Sector innovation characteristic; Innovation measurement; Innovation radar; Micro and small firm.

Data do recebimento do artigo: 08/08/2013

Data do aceite de publicação: 04/02/2014

Revista de Administração e Inovação, São Paulo, v. 11, n.1, p.115-137, jan./mar. 2014. 